\title{
Solid Phase Microextraction - Gas Chromatography for the Evaluation of Secondary Lipid Oxidation Products in Chicken Patties during Long-Term Storage
}

\author{
Lilian R. B. Mariutti, Gislaine C. Nogueira and Neura Bragagnolo* \\ Department of Food Science, Faculty of Food Engineering, University of Campinas, \\ 13083-862 Campinas-SP, Brazil
}

\begin{abstract}
A formação de hexanal, pentanal e malonaldeído em hambúrgueres de frango cru e grelhado durante o armazenamento a $-18{ }^{\circ} \mathrm{C}$ por 90 dias foi avaliada por microextração em fase sólida (SPME) utilizando fibras DVB/CAR/PDMS. As condições de extração foram otimizadas para obtenção de resultados reprodutíveis e evitar a saturação da fibra, mesmo para as amostras mais oxidadas. O desempenho de diferentes fibras DVB/CAR/PDMS foi verificado durante toda estocagem, sendo necessárias sete fibras para acompanhar o desenvolvimento da oxidação lipídica. O coeficiente de variação $(\mathrm{CV})$ foi calculado para 60 determinações em duplicata e não foram observadas diferenças $(\mathrm{p}<0,05)$ entre os $\mathrm{CV}$ das fibras independentemente do número de vezes que foram usadas. Os hambúrgueres crus apresentaram correlações de Pearson significativas $(\mathrm{p}<0,05)$ entre todos os parâmetros analisados, variando entre 0,93 e 0,99. Entretanto, para os hambúrgueres grelhados, apenas a correlação de 0,98 entre hexanal e pentanal foi significativa.
\end{abstract}

The formation of hexanal, pentanal and malonaldehyde from raw and grilled chicken patties during storage at $-18^{\circ} \mathrm{C}$ for 90 days was evaluated by SPME using a DVB/CAR/PDMS fiber. The extraction conditions were optimized to provide reproducible results and avoided fiber saturation even for more oxidised samples. The performance of different DVB/CAR/PDMS fibers was verified during the entire storage period and seven separate fibers were used to assay the extent of lipid oxidation. The relative standard deviation (RSD) was calculated for 60 duplicate analysis and no differences were observed ( $p>0.05$ ) among the fibers RSD despite the number of times they were used. The relationship between the different parameters were also established and compared to the results obtained by the traditional TBARS test. Raw patties showed significant $(\mathrm{p}<0.05)$ Pearson's correlations between all parameters, varying from 0.93 to 0.99 . However, grilled patties presented a correlation of 0.98 only between hexanal and pentanal.

Keywords: long term storage, lipid oxidation,TBARS, SPME, chicken meat

\section{Introduction}

Solid phase microextraction (SPME) is a solvent free sampling technique introduced in the 1990s by Arthur and Pawliszyn ${ }^{1}$ and has successfully been used in the determination of volatile profile of foodstuffs ${ }^{2-6}$ and also to follow the extent of lipid oxidation by the measure of secondary products, mainly in meat and meat products. ${ }^{7-12}$ Although there are some limitations of interfiber comparisons, SPME technique was successfully applied for extended time-course experiments for monitoring volatile compounds in olive oil. ${ }^{13}$

\footnotetext{
*e-mail: neura@fea.unicamp.br
}

The autoxidation process in food is a complex phenomenon induced by oxygen in the presence of initiators such as heat, free radicals, light, photosensitizing pigments and metal ions, which generate hydroperoxides and volatile compounds, generally through a process consisting of three phases: initiation, propagation and termination. During the initiation phase, unsaturated fatty acids suffer a homolytic breakdown of the hydrogen-carbon bond in $\alpha$ position relative to the double bond, resulting in the formation of highly unstable free radicals that stabilize by abstracting an hydrogen from another chemical species. In the presence of oxygen, free radicals react quickly with the triplet oxigen $\left({ }^{3} \mathrm{O}_{2}\right)$ generating other radical species, such as the peroxyradicals. The propagation phase comprises continuation and acceleration of this chain reaction, increasing hydroperoxides formation. 
The termination phase is characterized by the reaction between free radicals generating stable nonradical species and transformation of hydroperoxides into secondary nonradical oxidation compounds, such as hydrocarbons, aldehydes, alcohols and ketones.

Decomposition of lipid hydroperoxides is associated to the formation of a large variety of aldehydes that are responsible for off-flavors development in food. The most abundant aldehydes formed are 4-hydroxynonenal, hexanal, pentanal, propanal and malonaldehyde. Hexanal is mainly generated as a consequence of oxidative decomposition of polyunsaturated fatty acids (PUFA), and has been used as an indicator of oxidative stability and flavor acceptability and also to follow lipid oxidation in food systems. ${ }^{7-12,14}$ Malonaldehyde, a three carbon dialdehyde with carbonyl groups at the $\mathrm{C} 1$ and $\mathrm{C} 3$ positions, is a minor product of PUFA autoxidation derived from hydroperoxides formed from PUFA with three or more double bonds. In this sense, chicken meat is highly susceptible to lipid oxidation as it has a high proportion of unsaturated fatty acids.

The aim of the present study was to optimize the conditions for the extraction of hexanal, pentanal and malonaldehyde from chicken meat using SPME technique as a method to follow the development of lipid oxidation during long term storage. The relationship between different parameters was also established and compared to results obtained by traditional TBARS test.

\section{Experimental}

\section{Chemicals and reagents}

Hexanal (99\%) and 2-heptanone (99\%) were from SigmaAldrich (St Louis, MO, USA); pentanal (97\%), from Fluka (Steinheim, Germany), and 1,1,3,3-tetraethoxypropane (TEP, for synthesis), from Merck (Darmstadt, Germany). All other reagents were analytical grade.

\section{Preparation of chicken patties}

Twenty five 4-week old chickens (Cobb) were slaughtered and the breasts were minced in a food processor after the removal of the skin, bones and apparent fat and connective tissues. Thirty patties $(60 \pm 1 \mathrm{~g})$ were molded, and half of them was grilled at $165^{\circ} \mathrm{C}$ for 4 min each side, until core temperature reached $70{ }^{\circ} \mathrm{C}$. The internal temperature was monitored using a digital calibrated thermometer (Traceable Long-Stem, VWR, Friendswood, TX, USA). Raw and grilled patties were packed in polyethylene bags permeable to oxygen and stored in the dark at $-18{ }^{\circ} \mathrm{C}$ for 90 days.

\section{Optimization of secondary lipid oxidation volatiles} extraction by SPME

The optimization of the volatiles derived from lipid oxidation was carried out in a $7 \mathrm{~mL}$ flask and using a divinylbenzene-carboxen-polydimethylsiloxane (DVB/CAR/ PDMS) 50/30 $\mu \mathrm{m}$ SPME fiber (Supelco, Bellefonte, PA, USA). Different parameters were tested to optimize the method: weight of the sample $(0.5,1$ and $2 \mathrm{~g})$, water addition $(0,3$ and $6 \mathrm{~mL}$ ), addition of butylated hydroxyanisole (BHA) $(0,5$ and $10 \mathrm{mg})$, time of fiber exposure in the headspace $(5,10,15$, $20,30,40$, and $60 \mathrm{~min})$ and temperature of extraction $\left(60^{\circ} \mathrm{C}\right.$ and $80^{\circ} \mathrm{C}$ ). Before analysis, the fibers were preconditioned in the GC injection port as indicated by the manufacturer.

\section{GC analysis}

After volatiles extraction in the headspace, the fiber was removed from the vial and inserted directly into the injection port at $250^{\circ} \mathrm{C}$ of a Shimadzu gas chromatograph (GC 2010, Kyoto, Japan), equipped with a flame ionization detector at $280{ }^{\circ} \mathrm{C}$. The sampling time was $1 \mathrm{~min}$, although the fiber was kept in the injection port during all the running time. The injection port was in splitless mode. The column (DBWAX, $30 \mathrm{~m} \times 0.25 \mathrm{~mm}$ i.d., $0.25 \mu \mathrm{m}$, J\&W, Folsom, CA, USA) temperature varied from $40^{\circ} \mathrm{C}$ to $180^{\circ} \mathrm{C}$ at $4{ }^{\circ} \mathrm{C} \mathrm{min}{ }^{-1}$, remaining at $180^{\circ} \mathrm{C}$ for $2 \mathrm{~min} .{ }^{12}$ The flow control mode was linear velocity set at $47.3 \mathrm{~cm} \mathrm{~s}^{-1}$, with carrier gas $\mathrm{H}_{2}$, make up gas $\mathrm{N}_{2}$ at $30 \mathrm{~mL} \mathrm{~min}{ }^{-1}$ and air flow at $400 \mathrm{~mL} \mathrm{~min}^{-1}$. A narrow-bore glass liner of $0.75 \mathrm{~mm}$ i.d. (Supelco, Bellefonte, PA, USA) was used in substitution of common liners to improve peaks resolution. Identification was done by comparison of the retention time of the peaks of interest to the retention time of authentic standards and co-chromatography. Quantification was done using 2-heptanone as internal standard. Blank samples were regularly made to check possible carryover and the described desorption conditions ensure total desorption from fiber. The reported values are means of duplicate measurements.

\section{Analysis of thiobarbituric acid reactive substances}

The thiobarbituric acid reactive substances (TBARS) were determined in $5.00 \pm 0.05 \mathrm{~g}$ samples of homogenized meat according to the method of Vyncke ${ }^{15,16}$ with some modifications. ${ }^{17}$ TBARS were expressed in $\mu \mathrm{g}$ of malonaldehyde equivalent per $\mathrm{kg}$ of dry meat using a standard curve (concentration range from 0.10 to $\left.8.0 \mu \mathrm{mol} \mathrm{L}{ }^{-1}, y=0.0826 x+0.0068, \mathrm{R}^{2}=0.9999\right)$ established using 1,1,3,3-tetraethoxypropane. The reported values are means of duplicate measurements. 


\section{Moisture content}

Moisture content was determined according to AOAC method $950.46 .^{18}$

\section{Statistical analysis}

The software Statistica for Windows 5.5 (StatSoft Inc., OK, USA) was used to calculate the Pearson's correlation coefficients between the secondary oxidation products. The RSD means were compared by Tuckey's test (confidence level of $95 \%$ ).

\section{Results and Discussion}

\section{Optimization of SPME conditions}

The formation of hexanal, pentanal and malonaldehyde from chicken meat oxidation was evaluated using a DVB/ CAR/PDMS fiber. The DVB/CAR/PDMS fiber is made of a layer of PDMS-CAR, where small molecules with high diffusion coefficients are adsorbed onto the Carboxen, and is also covered by a second layer of PDMS-DVB, where the heavier molecules are retained in the outer of the DVB layer. ${ }^{19}$ This fiber has previously shown more affinity to aldehyde compounds than CAR/PDMS fiber which was better to evaluate ester compounds. ${ }^{2} \mathrm{DVB} / \mathrm{CAR} /$ PDMS fiber was also used for hexanal determination in frankfurters ${ }^{8}$ and pressurized chicken; ${ }^{12}$ while CAR/PDMS fiber was used for hexanal determination in pressurized chicken, ${ }^{7}$ PDMS/DVB fiber was used for hexanal and pentanal determination in cooked turkey, ${ }^{9}$ and PDMS fiber was used for hexanal determination in freeze dried chicken myofibrils ${ }^{10}$ and minced pork. ${ }^{11}$

Addition of water, $3 \mathrm{~mL}$ or $6 \mathrm{~mL}$ and use of magnetic stirring to improve volatile extraction, led to an increase in the number of peaks in the GC chromatogram, showing the release of diverse volatile compounds in high amounts and interfering in the quantification of aldehydes of interest in the present study. Besides, when any concentration of internal standard (2-heptanone) and water were added to the sample, the fiber was saturated by the 2-heptanone. In this case, the GC chromatogram presented a huge peak at $7.08 \mathrm{~min}, 2$-heptanone retention time, and the peaks of malonaldehyde, pentanal and hexanal remained always with the same area despite of the degree of oxidation of the meat. 2-Heptanone was easily transferred to headspace from water once it was free in the matrix. To overcome this problem, no water was added to the sample and no agitation was performed. Addition of $10 \mu \mathrm{L}$ of internal standard solution was done directly to the meat in the vial, and after the vial was closed, the mixture was homogenized by shaking.

Similarly, when temperature was risen from $60{ }^{\circ} \mathrm{C}$ to $80{ }^{\circ} \mathrm{C}$, volatile extraction was also increased and the appearance of new peaks in the GC chromatogram had impaired quantification of malonaldehyde, pentanal and hexanal. Moreover, when the fiber exposure time exceed $30 \mathrm{~min}$ at $80^{\circ} \mathrm{C}$, fiber saturation occured.

Use of BHA as antioxidant did not show any effect on the release of secondary products of lipid oxidation regardless of extraction temperature, time of fiber exposure in the headspace or water addition.

For each analysis, the SPME fiber was introduced into the vial headspace and held for different time periods to determine the effect of duration of sampling on pentanal, hexanal and malonaldehyde uptake at $60^{\circ} \mathrm{C}$ (Figure 1). A competition between water vapour and hydrophobic oxidation products for active sites on the fiber may occur and this may take time to reach equilibrium. ${ }^{20}$

Finally, an optimised extraction procedure was defined: two grams of sample were weighted into a $7 \mathrm{~mL}$ vial, $10 \mu \mathrm{L}$ of internal standard (2-heptanone, $81.3 \mu \mathrm{g} \mathrm{mL}^{-1}$ ) was added and the vial was sealed with a teflon septum secured by an aluminum cap and gently shaked for homogenization. The SPME fiber was introduced through the septum into the headspace and the vial was heated in a water bath at $60{ }^{\circ} \mathrm{C}$ for $10 \mathrm{~min}$. After extraction, the fiber was immediately injected at the GC to avoid contamination. These conditions provided reproducible results and avoided fiber saturation even for more oxidised samples. Figure 2 shows a typical chromatogram of volatile aldehydes extracted by SPME from a chicken sample.

The SPME technique presents some limitations. Usually, there is good reproducibility when using a single fiber on routine analysis, whereas reproducibility is poor when using different fibers, especially from different batches. ${ }^{21}$ The use of different fibers in a study can affect the results, and most comparative studies are performed using a single fiber. ${ }^{22,23}$ For these reasons, after establishing the extraction conditions, the performance of different DVB/ CAR/PDMS fibers was also verified. The course of lipid oxidation was followed in raw and grilled chicken patties stored at $-18^{\circ} \mathrm{C}$ during 90 days using the developed method for malonaldehyde, pentanal and hexanal determinations. During the entire storage period, seven different fibers were necessary to assay the extent of lipid oxidation, and a single fiber was used 21.7 times, in average, and 30 times maximum. The relative standard deviation (RSD) was calculated for 60 duplicate analysis, in a total of 120 determinations (Table 1), and each duplicate analysis 

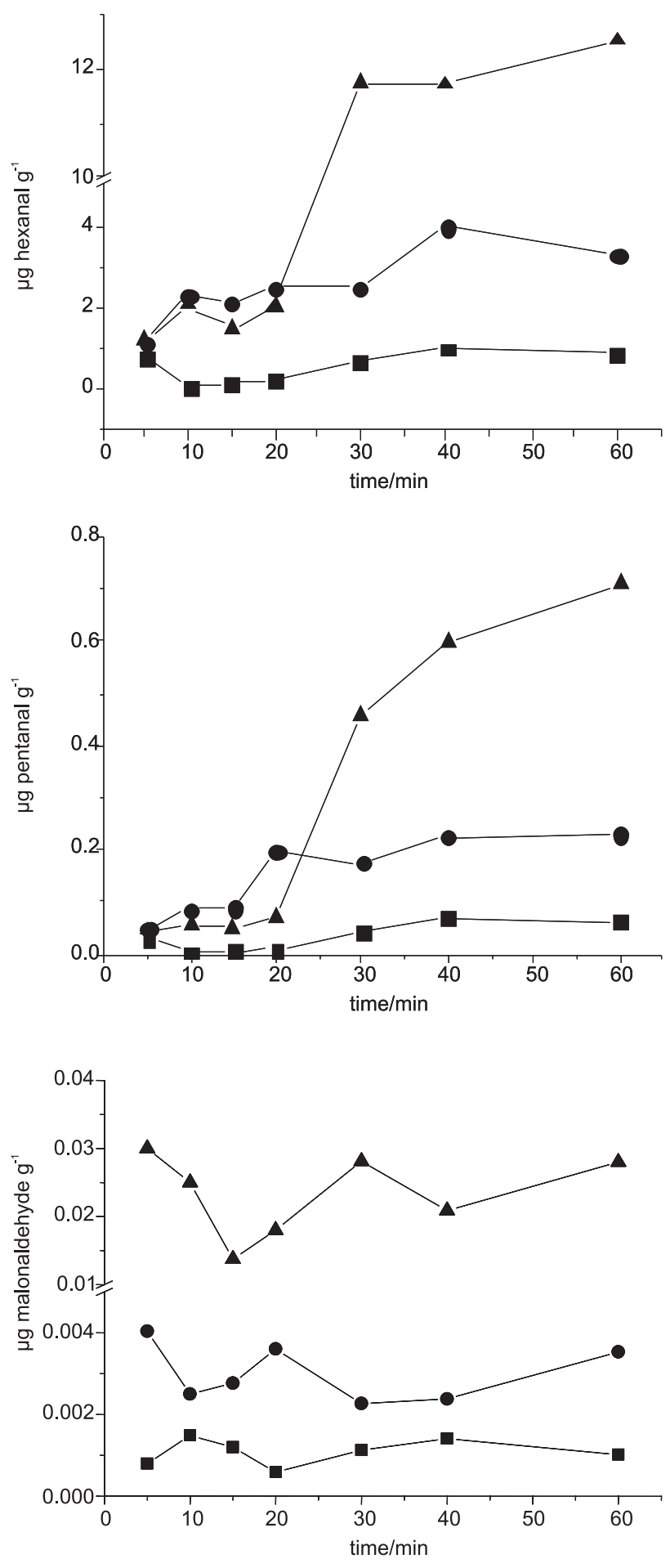

Figure 1. Effect of sample weight and sampling time on pentanal, hexanal and malonaldehyde uptake by DVB/CAR/PDMS SPME fibers at $60^{\circ} \mathrm{C}$ from the headspace of chicken meat: $(\boldsymbol{\square}) 0.5 \mathrm{~g},(\mathbf{O}) 1 \mathrm{~g},(\boldsymbol{\Delta}) 2 \mathrm{~g}$.

was performed using the same fiber. No differences were observed ( $p>0.05$ ) among the RSD of the fibers despite the number of times they were used. In general, malonaldehyde showed the highest RSD (12.5\%, in average), while pentanal and hexanal presented lower RSD values $(9.6 \%$

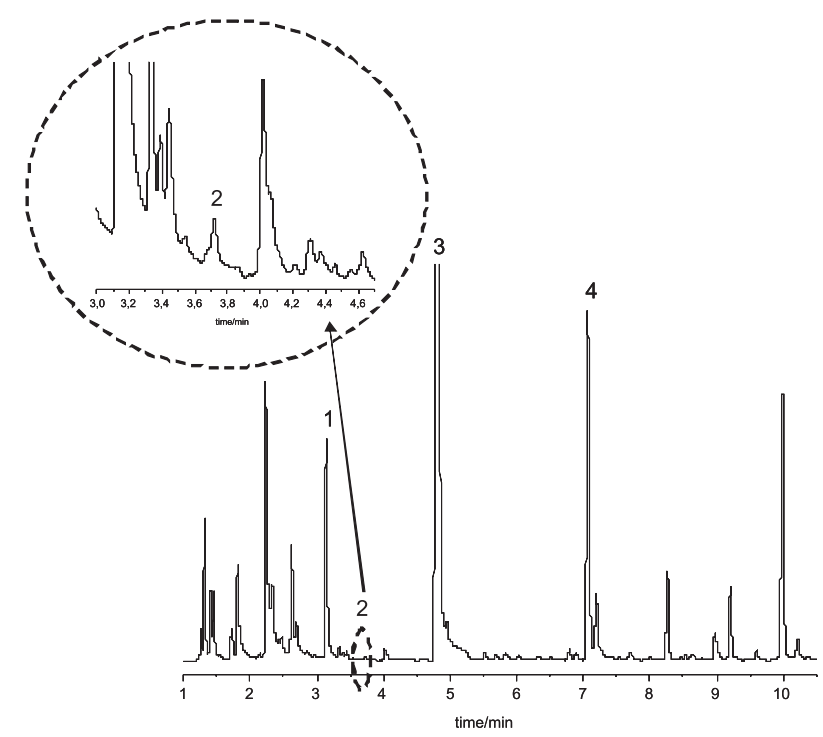

Figure 2. GC-FID chromatogram of the volatile aldehydes extracted from a chicken sample. Peaks: 1 = pentanal, $2=$ malonaldehyde, $3=$ hexanal and $4=2$-heptanone.

and $8.9 \%$, in average). The distribuition of the RSD according to the use was plotted for the four fibers that were used 30 times each (Figure 3 ) and, with a few exceptions, the RSD values were below $20 \%$ which is acceptable for SPME semi-quantitative analysis. However, it is important to note that single fibers could respond differently for the same analysis; for example, fiber D (Figure 3) did not present any RSD above $20 \%$ for any of the three analysed aldehydes, while the other fibers presented at least one RSD above $20 \%$ for one determination. Variations due to samples were minimized once new or aged fibers were used randomly to determine the oxidative status in fresh and oxidised samples. Kalua et al..$^{13}$ has also successfully used a SPME-GC method to monitor volatile compounds in olive oil stored in the light for 12 months using three separate fibers.

\section{Formation of secondary lipid oxidation products in chicken meat during storage}

Raw and grilled chicken patties were analysed for secondary lipid oxidation products formation by SPME and TBARS test during storage at $-18{ }^{\circ} \mathrm{C}$ for 90 days (Figure 4). The TBARS test is a method based on the spectrophotometric determination of malonaldehyde commonly used for assessing lipid oxidation in foods. TBARS reaction is not specific for malonaldehyde because TBA reacts with many different carbonyl compounds formed during lipid oxidation, therefore, TBARS test can be used to assess the extent of lipid oxidation in general, rather than to quantify malonaldehyde. . $-9,11,14,24^{-1}$ 

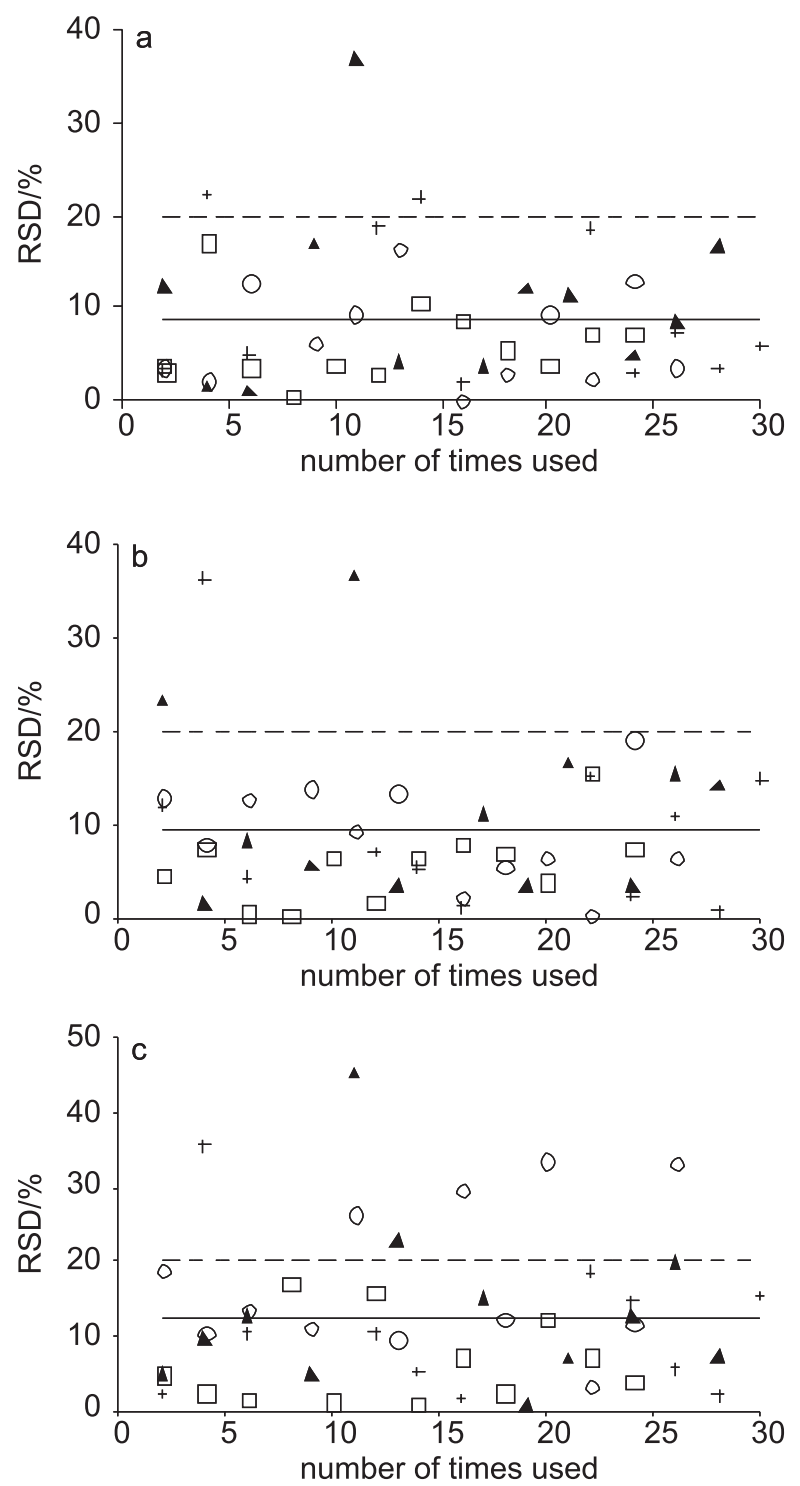

Figure 3. Relative standard deviations (RSD) of duplicate measurements using four different fibers, for (a) hexanal, (b) pentanal and (c) malonaldehyde determinations in chicken meat: $(\boldsymbol{A})$ fiber $\mathrm{A},(\mathrm{O})$ fiber B, (+) fiber C, and ( $\square)$ fiber D.

Table 1 - Performance of DVB/CAR/PDMS fibers ${ }^{a}$ during a 90 days storage experiment

\begin{tabular}{lcccc}
\hline $\begin{array}{l}\text { Number of } \\
\text { times used }\end{array}$ & $\mathrm{n}^{b}$ & \multicolumn{3}{c}{ RSD $(\%)$} \\
\cline { 3 - 5 } & & hexanal & pentanal & malonaldehyde \\
\hline $1-5$ & 10 & 7.9 & 13.1 & 12.6 \\
$6-10$ & 11 & 8.3 & 7.9 & 11.7 \\
$11-15$ & 10 & 13.5 & 11.5 & 14.5 \\
$16-20$ & 11 & 7.3 & 6.1 & 13.4 \\
$21-25$ & 10 & 7.9 & 9.3 & 9.8 \\
$26-30$ & 8 & 8.7 & 9.8 & 13.3 \\
average use & 60 & 8.9 & 9.6 & 12.5 \\
\hline
\end{tabular}

${ }^{a}$ data is refers to 7 single fibers. ${ }^{b}$ number of duplicate samples analyzed.
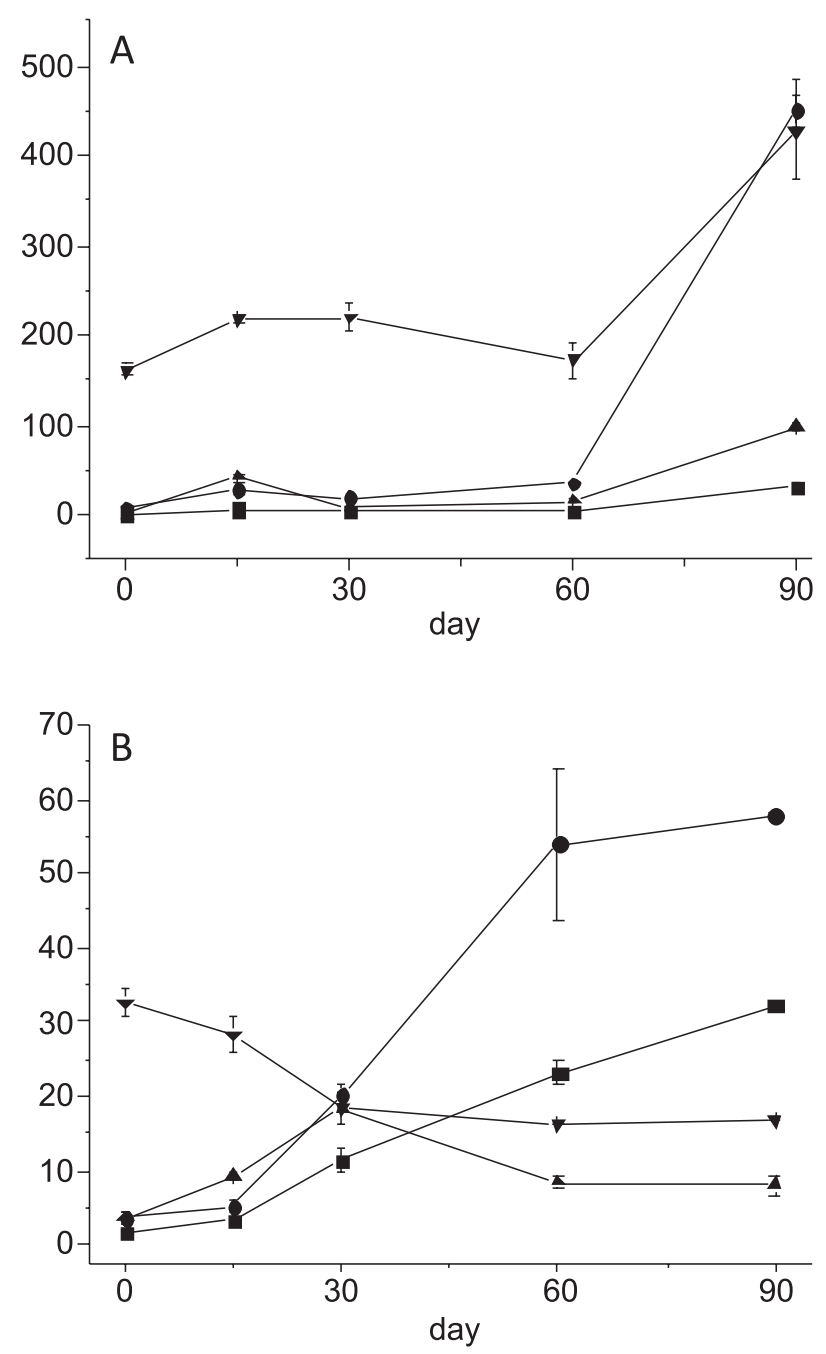

Figure 4. Formation of secondary lipid oxidation products in chicken meat during storage at $-18^{\circ} \mathrm{C}$ for 90 days in the dark: (A) - - pentanal $\left(\mu \mathrm{g} \mathrm{kg}^{-1}\right.$ of dry meat), - - hexanal ( $\mu \mathrm{g} \mathrm{kg}^{-1}$ of dry meat), - $\mathbf{\Delta}$ - malonaldehyde ( $\mu \mathrm{g} \mathrm{kg}^{-1}$ of dry meat), and $-\boldsymbol{\nabla}$ - TBARS ( $\mu \mathrm{g}$ malonaldehyde equivalent $\mathrm{kg}^{-1}$ of dry meat) in raw chicken; and (B) - - pentanal $\left(10^{-1} \mu \mathrm{g} \mathrm{kg}^{-1}\right.$ of dry meat), - - hexanal $\left(10^{-2} \mu \mathrm{g} \mathrm{kg}{ }^{-1}\right.$ of dry meat $),-\boldsymbol{\Delta}$ - malonaldehyde $\left(\mu \mathrm{g} \mathrm{kg}^{-1}\right.$ of dry meat), and - $\boldsymbol{\nabla}$ - TBARS $\left(10^{-1} \mu \mathrm{g}\right.$ of malonaldehyde equivalent $\mathrm{kg}^{-1}$ for dry meat) in grilled chicken. Means values \pm standard deviation of two samples.

Raw patties showed an increase in all analysed aldehydes after 60 days of storage, especially for TBARS and hexanal, resulting in significant $(\mathrm{p}<0.05)$ correlations between all parameters, varying from 0.93 and 0.99 (Table 2). The slow rate of lipid oxidation in raw samples was mainly due to mechanical processing, which disrupted the muscle membrane structure, and resulted in exposure of labile phospolipids to oxygen, enzymes, heme pigments, and metal ions.

The grilled patties presented distinct behaviours for the different aldehydes measured. TBARS decreased from day 0 to day 60 and after that remained stable. Malonaldehyde presented a peak value at day 30 , and 
Table 2 - Pearson correlation coefficients for the lipid oxidation analysis of raw and grilled chicken during storage at $-18{ }^{\circ} \mathrm{C}$ for 90 days

\begin{tabular}{lcc}
\hline Correlation & Raw chicken & Grilled chicken \\
\hline Pentanal vs. hexanal & $0.99^{*}$ & $0.98^{*}$ \\
Pentanal vs. malonaldehyde & $0.97 *$ & 0.05 \\
Pentanal vs. TBARS & $0.98^{*}$ & -0.43 \\
Hexanal vs. malonaldehyde & $0.93^{*}$ & 0.02 \\
Hexanal vs. TBARS & $0.97 *$ & -0.53 \\
Malonaldehyde $v s$. TBARS & $0.95^{*}$ & -0.64 \\
\hline
\end{tabular}

${ }^{*}$ Correlation coefficients were statistically significant $(\mathrm{p}<0.05)$.

then decreased, while hexanal and pentanal were still increasing at day 90. Besides the mechanical processing, grilled samples suffered thermal treatment, which accelerated the development of lipid oxidation. TBARS and malonaldehyde did not show significant correlation between each other nor hexanal nor pentanal.TBARS and malonaldehyde were formed in low contents and the decrease in their contents suggested the occurence of degradation or reaction with other compounds, such as proteins. On the other hand, a significant $(\mathrm{p}<0.05)$ correlation of 0.98 (Table 2) was verified between hexanal and pentanal, both compounds are known to be markers of the termination phase of lipid oxidation.

The occurence of correlations between TBARS and volatile aldehydes measured by SPME in meat products was found by other authors and summarized in Table 3. The comparison among the results is very difficut since the reported correlations are referred to different meat products during chill storage, at temperatures around $4{ }^{\circ} \mathrm{C},{ }^{8-12}$ and these conditions were obviously prone to accelerate the rate of lipid oxidation more than the conditions applied in the present study. These methods are widely used as indicators of lipid oxidation and the pattern of hexanal and pentanal level was previously found to be more sensitive compared to TBARS to monitor lipid oxidation in poultry. ${ }^{13,14}$

\section{Conclusions}

The optimized assay is simple and do not require any solvent for extraction of the volatile aldehydes. The SPME technique was successfully applied in a long course storage experiment for monitoring lipid oxidation in chicken meat using separate single DVB-CAR-PDMS fibers.

\section{Acknowledgments}

The authors thank the State of São Paulo Research (FAPESP) and the The National Council for Scientific and Technological Development (CNPq) for financial support.

\section{References}

1. Arthur, C. L.; Pawliszyn, J.; Anal. Chem. 1990, 62, 2145.

2. Marco, A.; Navarro, J. L.; Flores, M.; Food Chem. 2004, 84, 633.

3. Elmore, J. S.; Mottram, D. S.; Hierro, E.; J. Chromatogr., A 2001, 905, 233.

4. Vichi, S.; Castellote, A. I.; Pizzale, L.; Conte, L. S.; Buxaderas, S.; Lopez-Tamames, E.; J. Chromatogr., A 2003, 983, 19.

5. Brunton, N. P.; Cronin, D. A.; Monahan, F. J.; Flavour Fragr. J. 2001, 16, 294.

6. Estevez, M.; Ventanas, S.; Ramirez, R.; Cava, R.; J. Agric. Food Chem. 2004, 52, 5168.

7. Beltran, E.; Pla, R.; Yuste, J.; Mor-Mur, M.; Meat Sci. 2003, 64, 19.

8. Estevez, M.; Ventanas, S.; Cava, R.; Food Chem. 2007, 100, 55.

9. Brunton, N. P.; Cronin, D. A.; Monahan, F. J.; Durcan, R.; Food Chem. 2000, 68, 339.

10. Goodridge, C. F.; Beaudry, R. M.; Pestka, J. J.; Smith, D. M.; J. Agric. Food Chem. 2003, 51, 4185.

11. Nielsen, J. H.; Sorensen, B.; Skibsted, L. H.; Bertelsen, G.; Meat Sci. 1997, 46, 191.

12. Wiggers, S. B.; Kroger-Ohlsen, M. V.; Skibsted, L. H.; Eur. Food Res. Technol. 2004, 219, 167.

Table 3 - Correlation coefficients between hexanal and pentanal determined by SPME and TBARS found in literature

\begin{tabular}{lccc}
\hline determination & correlation & significance & product \\
\hline hexanal vs. TBARS & 0.55 & $\mathrm{p}<0.01$ & raw frankfurters \\
hexanal vs. TBARS ${ }^{9}$ & 0.99 & $*$ & whole pieces of cooked turkey \\
pentanal vs. TBARS & 0.98 & $*$ & whole pieces of cooked turkey \\
hexanal vs. TBARS ${ }^{10}$ & 0.94 & $\mathrm{p}<0.05$ & freeze dried chicken myofibrils \\
hexanal vs. TBARS $^{11}$ & 0.98 & $*$ & pre-cooked minced pork 60 days \\
hexanal vs. TBARS & & $*$ & cooked pressurized chicken 6 days \\
\hline
\end{tabular}

* not available in the reference. 
13. Kalua, C. M.; Bedgood, D. R.; Prenzler, P. D.; Anal. Chim. Acta 2006, 556, 407.

14. Bragagnolo, N.; Danielsen, B.; Skibsted, L. H.; Eur. Food Res. Technol. 2005, 221, 610.

15. Vyncke, W.; Fette Seifen. Anstrichm. 1970, 72, 1084.

16. Vyncke, W.; Fette Seifen. Anstrichm. 1975, 77, 239.

17. Sørensen, G.; Jørgensen, S. S.; Z. Lebensm. Unter Forsch. 1996, 202, 205.

18. AOAC Official Methods of Analysis, $17^{\text {th }}$ ed., Association of Official Analytical Chemists, Gouthersburg, 2002.

19. Pillonel, L.; Bossett, J. O.; Tabacchi, R.; LWT-Food Sci. Technol. 2002, 35,1 .
20. Beltran, G.; Aguilera, M. P.; Gordon, M. H.; Food Chem. 2005, 92, 401.

21. Martos, P. A.; Pawliszyn, J.; Anal. Chem. 1997, 69, 206.

22. Grote, C.; Pawliszyn, J.; Anal. Chem. 1997, 69, 587.

23. Fabre, M.; Aubry, V.; Guichard, E.; J. Agric. Food Chem. 2002, 50, 1497.

24. Mariutti, L. R. B.; Orlien, V.; Bragagnolo, N.; Skibsted, L. H.; Eur. Food Res. Technol. 2008, 227, 337.

Received: September 15, 2008

Web Release Date: November 12, 2009

FAPESP helped in meeting the publication costs of this article. 